\title{
Peroral endoscopic myotomy for esophageal
}

\section{muscular ring}

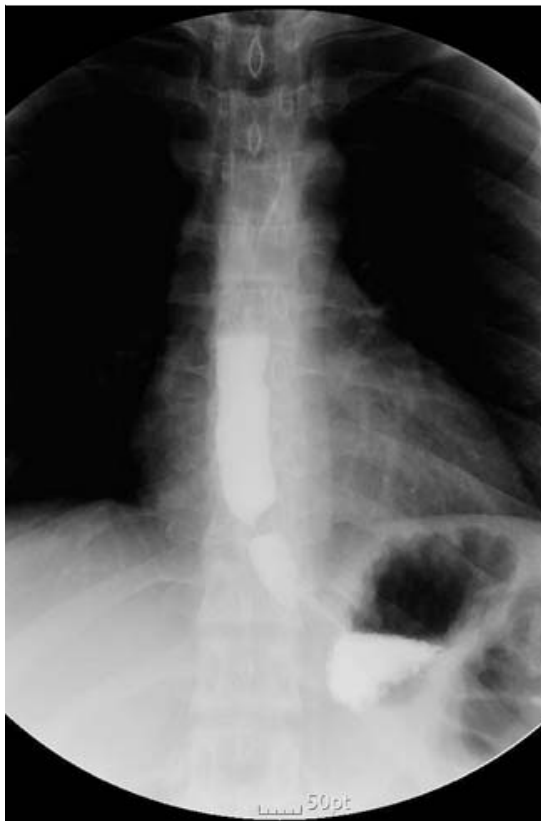

Fig. 1 Esophagography showing a focal concentric narrowing above the gastroesophageal junction in a 22-year-old man with a 5-year history of dysphagia.
Lower esophageal muscular ring, usually called A-ring, is a rare esophageal lesion that occasionally causes dysphagia or symptoms of reflux [1,2]. There have been only a few case reports of attempts to treat muscular ring with the intramuscular injection of botulinum toxin (botox) $[1,3]$. This report is believed to be the first of the use of peroral endoscopic myotomy (POEM) to treat esophageal muscular ring. A 22-year-old man presented with a 5 -year history of dysphagia, which occurred when he ate foods quickly. He had no history of related diseases, and his Eckardt score remained at 7. Esophagography demonstrated focal concentric narrowing above the gastroesophageal junction ( $\bullet$ Fig. 1). Upper gastrointestinal endoscopy showed a smooth esophageal narrowing with normal overlying mucosa situated $3 \mathrm{~cm}$ above the squamocolumnar junction ( $\bullet$ Fig.2). At endoscopic ultrasonography, the inner circular muscle layer at the level of the lesion was found to be thickened to $5.1 \mathrm{~mm}$ ( $\bullet$ Fig.3). Manometry showed a normal lower esophageal

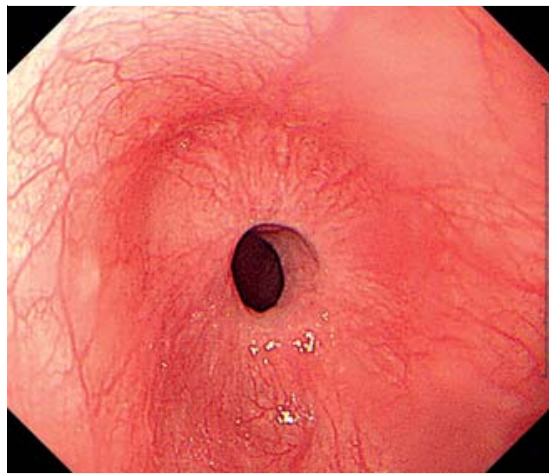

Fig. 2 Upper gastrointestinal endoscopy showing a smooth esophageal narrowing with normal overlying mucosa.

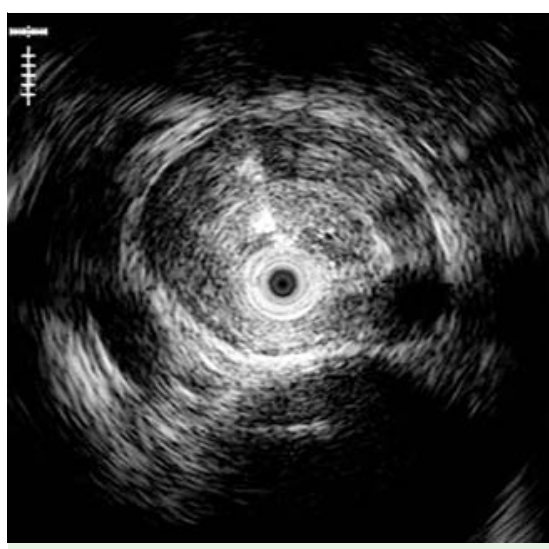

Fig. 3 Endoscopic ultrasonography showing the inner circular muscle layer thickened to $5.1 \mathrm{~mm}$.
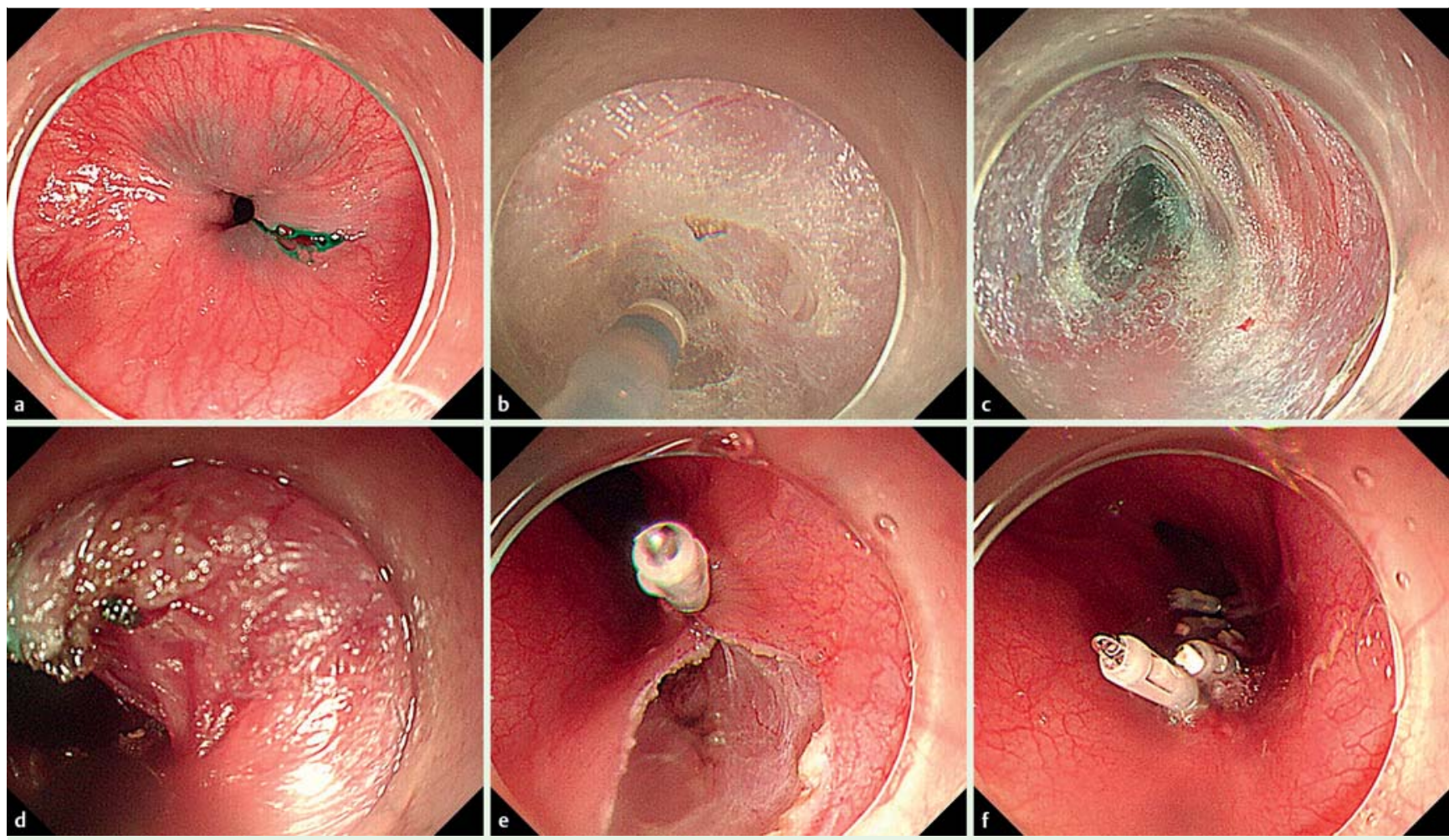

Fig. 4 Peroral endoscopic myotomy of the esophageal muscular ring. a Injection of indocyanine green into the submucosa just above the muscular ring. b, c Submucosal tunneling. $\mathbf{d}$ The 5-cm-long myotomy of the thickened esophageal muscle. e, $\mathbf{f}$ Closure of the mucosal entry by clipping. 


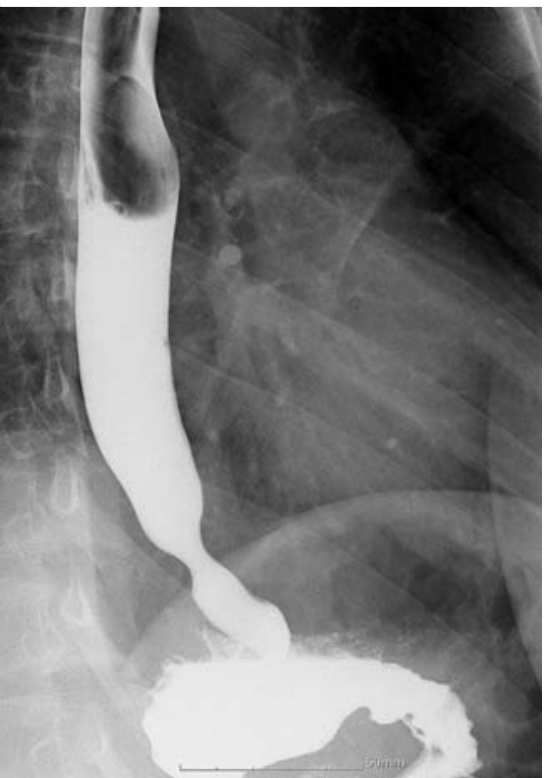

Fig.5 Esophagography showing the lumen widened at the previously stenotic site after peroral endoscopic myotomy.

sphincter pressure with normal relaxation (lower esophageal sphincter [LES] pressure $20 \mathrm{mmHg}$, integrated relaxation pressure [IRP] $8 \mathrm{mmHg}$ ). Contraction of the esophageal body was peristaltic, and after wet swallows, occasional multiplepeaked contractions of the distal esophageal body in high amplitude were noted. There was no evidence of distal esophageal spasm (distal contractile integral [DCI] $3682 \mathrm{mmHg} / \mathrm{s} / \mathrm{cm}$, distal latency [DL] $8.3 \mathrm{~s}$ ).

We diagnosed lower esophageal muscular ring and performed a POEM proce-

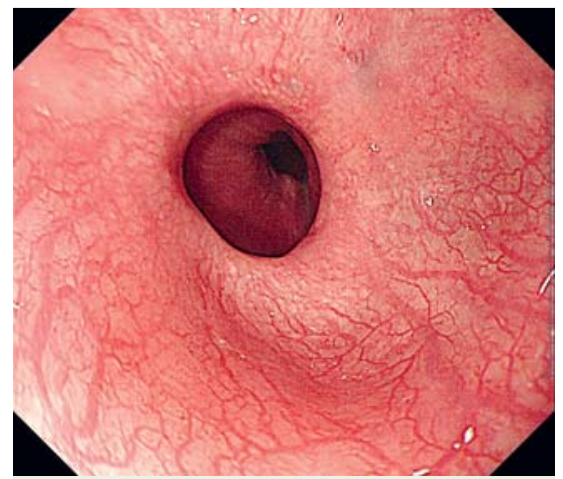

Fig. 6 Upper gastrointestinal endoscopy showing the dilated esophageal lumen after peroral endoscopic myotomy.

dure by the conventional tunneling method ( Fig.4a-c). The total length of the myotomy was $5 \mathrm{~cm}$ ( $\bullet$ Fig. $4 \mathrm{~d}-\mathbf{f}$ ). After the operation, esophagography and esophagogastroduodenoscopy showed the lumen to be widened at the previous stenotic site ( Fig.5, $\bullet$ Fig. 6). At 1 month after POEM, the patient revisited our clinic and reported disappearance of the dysphagia (Eckardt score 0 ).

This case demonstrates an obviously positive response to our treatment, with no specific complications after the entire operational procedure. However, controlled trials with long-term follow-up are necessary to establish POEM as a standard treatment for esophageal muscular ring.

Endoscopy_UCTN_Code_TTT_1AO_2AN

Competing interests: None

\section{Ga Won Song, Weon Jin Ko, Won Hee Kim, Ki Baik Hahm, Sung Pyo Hong, Joo Young Cho}

Digestive Disease Center, CHA Bundang Medical Center, CHA University, Seongnam-si, Korea

\section{References}

1 Varadarajulu S, Noone T. Symptomatic lower esophageal muscular ring: response to botox. Dig Dis Sci 2003; 48: 2132 -2134

2 Park KC, Kwon JG, You GJ et al. A case of lower esophageal muscular ring presenting with dysphagia [in Korean]. Korean J Gastroenterol 2003; 42: 539-543

3 Perez-Arroyo H, Hunter J, Waring JP. Botulinum toxin injection for an esophageal muscular A-ring. Gastrointest Endosc 1997; 45: 193-195

\section{Bibliography}

DOI http://dx.doi.org/

10.1055/s-0034-1392596

Endoscopy 2015; 47: E387-E388

(c) Georg Thieme Verlag KG

Stuttgart · New York

ISSN 0013-726X

\section{Corresponding author}

\section{Joo Young Cho, MD, PhD}

CHA University Bundang Medical Center

59 Yatapro

Bundang-gu

Seongnam-si

Korea

Fax: +82-31-780-5000

cjy6695@dreamwiz.com 